\title{
Realization of sweet cherry varieties productivity in stressful conditions in the south of Russia
}

\author{
Rimma Zaremuk, Yulia Dolya*, and Tatiana Kopnina \\ Federal State Budget Scientific Institution «North Caucasian Federal Scientific Center of \\ Horticulture, Viticulture, Wine-making», 39 str. 40 Let Pobedy, Krasnodar, 350901, Russia
}

\begin{abstract}
The main stress factors for sweet cherries in the Krasnodar region are: late return frosts and early exposure to frost after a warm autumn. Against the background of late return frosts, the death of the generative organs of sweet cherry was $95 \%$, the realization of the productive potential $-3.3 \%$; after early spring frosts, freezing of cherry fruit buds was $30 \%$, the realization of productive potential $-47.8 \%$. The early impact of frost after a warm autumn, the death of the generative organs of sweet cherry was $90 \%$, the realization of the productive potential $-5.6 \%$. Under favorable weather conditions, i.e. in the absence of any type of stress, the yield of sweet cherry varieties reached $40.5 \mathrm{~kg} / \mathrm{tree}$ or $27 \mathrm{t} / \mathrm{ha}$, and the implementation of the production potential $-57.8 \%$. Mathematical analysis showed a high correlation $\left(\mathrm{R}^{2}=0.97\right)$ of the yield of varieties from the abnormal temperatures in March and the degree of exposure to stress, i.e. damage to generative organs $\left(\mathrm{R}^{2}=0.9\right)$. Domestic varieties Alaya, Sashenka and Volshebnitsa, can be recommended for creating sustainable plantations in the south of Russia.
\end{abstract}

\section{Introduction}

Sweet cherry belongs to fruit crops characterized by high temperature requirements. Possessing a high potential for productivity, sweet cherries are susceptible to weather anomalies of various origins and under the annual influence of stressors, the realization of its productivity even in the southern regions, according to some data, is at the level of $50 \%$ $[1,2]$.

Krasnodar region is one of the regions of Russia with a favorable climate for growing cherries. At the same time, a distinctive feature of the region is the frequent manifestation of stress factors - a long frost-free period or warm winters, sudden temperature drops during the dormant period, recurrent spring frosts, abnormally high temperatures and drought in summer, etc.

It is obvious that under such conditions the adaptability of varieties changes, i.e. its "imbalance" occurs, which manifests itself, first of all, in a decrease in plant productivity

\footnotetext{
* Corresponding author: skzniisiv2015@mail.ru
} 
$[3,4]$. This tendency calls for the development of measures and methods for increasing the resistance of fruit plants [5]. One of the ways to solve this problem is to create varieties of a new generation with a high potential for resistance to different types of stress factors based on new knowledge, identified features of the implementation of the biopotential of sweet cherry, various research methods [6,7].

Some scientists believe that the assessment of the adaptive potential should be carried out primarily by physiological methods, based on the fact that such characteristics of fruit crops as productivity and resistance to stress are antipodes, since the same physiological mechanisms are involved in their implementation [8,9]. A number of researchers are inclined to believe that the most accurate and complete characterization of stress resistance can be obtained by assessing the productivity of varieties both under favorable and stressful conditions $[1,10]$.

It is known that the degree of realization of the productivity potential of many fruit crops will be complicated by the impact of low negative temperatures [11,12]. For the sweet cherry culture, at least two types of stress factors have been identified: these are abnormally low temperatures during the dormant period and annual spring frosts during the flowering period $[1,4,13]$. Some researchers, one of the possible conditions for the full realization of the productivity of sweet cherry, consider varietal resistance to the effects of abnormal frosts at the beginning of winter, when the level of yield loss can reach $80-100 \%$ $[14,15]$. There is an opinion that the third and fourth components of the winter hardiness of fruit plants are the main ones. The third component indicates the ability of the variety to maintain resistance in winter, and the fourth - resistance to spring frosts [2,13].

However, it is obvious that cherry varieties are of significant value, combining high resistance to a large number of components of winter hardiness. The identification of such is possible on the basis of assessing the degree of the damaging factor under the direct influence of stress, which determines the relevance of studies that allow determining the phenotypic adaptability of sweet cherry varieties. And also to clarify the indicators and parameters at which the varieties can realize their production potential. Based on the relevance of the research, the goal of the research was determined - to assess the adaptability of sweet cherries under the conditions of the annual exposure to stresses of various types and to identify varieties that maximize their productivity potential in the conditions of the southern region.

\section{Material and method}

The research was carried out in the Prikubanskaya fruit growing zone of the Krasnodar region on the basis of the Tsentralnoye OPH (Krasnodar) and the Center for Collective Use - the collection of fruit crops NCFSCHVW. The objects of research were 15 varieties of sweet cherry (Cerasus avium L.) - 11 varieties of selection NCFSCHVW, 4 introduced varieties. Control for early varieties - Krasnodarskaya ranjaya, medium early Kavkazskaya, medium - Volshebnitsa, late - Alaya. Variety is an option. Repetition is 3 times. Planting scheme 5 × $3 \mathrm{~m}$. Stock - cherry seedlings.

Krasnodar region is located in the temperate continental zone, characterized by hot dry summers and mild winters with little snow. The soil and climatic conditions of the region are favorable for the cultivation of sweet cherries. The soils of the experimental site are represented by leached chernozems, the density of the humus horizon is $1.30-1.42 \mathrm{~g} / \mathrm{cm}^{3}$, the humus content is $3.47 \%$, pHwater. 6.8-7.2. Groundwater is at a level of $6 \mathrm{~m}$.

Weather conditions in 2017-2020 were ambiguous. So the average annual temperature was high and amounted to $+13.2+13.4^{\circ} \mathrm{C}$, which exceeded the average annual indicators by $1.0-2.0^{\circ} \mathrm{C}$. Precipitation was in the range of $577.0-702.0 \mathrm{~mm}$, which corresponds to the GTC $0.7-0.8$ and indicates their lack. The lowest winter temperatures $\left(-23.0^{\circ} \mathrm{C}\right)$ were 
recorded in the 3rd decade of January 2017 , in the 1st decade of February $2020\left(-14.0^{\circ} \mathrm{C}\right)$; spring frosts in the 2nd decade of March 2019 (-3.0-3.5 $\left.{ }^{\circ} \mathrm{C}\right)$, in the 2nd decade of March $2020\left(-5.0-6.0^{\circ} \mathrm{C}\right)$ and the 2 nd decade of April $\left(-4.0-5.0^{\circ} \mathrm{C}\right)$. An abnormal air temperature of $+39.0^{\circ} \mathrm{C}$ was noted in the third decade of June 2018 and in the first decade of August 2017.

The yield from each repetition (tree) was calculated by the formula: $\mathrm{Y}=\mathrm{A} / \mathrm{B} \times 100$, where $\mathrm{A}$ is the average yield from 1 tree, $\mathrm{kg} ; \mathrm{B}$ - feeding area of 1 tree $\left(\mathrm{m}^{2}\right) ; 100-$ coefficient of conversion of weight in $\mathrm{kg}$ to weight in tons and area $\mathrm{m}^{2}-$ in hectares. The feeding area of 1 cherry tree (B) is $5 \times 3 \mathrm{~m}=15 \mathrm{~m}^{2}$. The percentage of reduction of fruit buds (buds, flowers) was determined by the formula: $\mathrm{P}=$ Hp. / p.p. $\mathrm{x} 100 \%$; where H.p. death of fruit buds, pp. - the number of all recorded fruit buds. Potential yield is calculated using the formula: PUNA $1 \mathrm{~m}=\mathrm{CC}$ (pcs.) X Sv. (\%) x MP (g), where CC is the number of flowers; $\mathrm{Sv}$ - flower ovary, MP - weight of the fetus. The realization of biological potential is determined by the formula RBP $=\mathrm{FU} / \mathrm{PU} \times 100 \%$, where FU is the actual yield; PU potential yield ( $70 \mathrm{~kg} /$ tree).

Statistical processing of the data was carried out in the standard Microsoft Excel software package (2013), to interpret the data obtained from regression statistics, the following indicators were used: arithmetic mean (Xma.), multiple R, R-square, normalized $\mathrm{R}$, standard error, $\mathrm{LSD}_{0,5}$ with reliable probability $95 \%$.

\section{Results and discussion}

The productivity of sweet cherry varieties of various ecological-geographical and genetic origin was studied in the years when the following emerged: critical winter temperatures for sweet cherries $\left(-23.0^{\circ} \mathrm{C}\right)$ at the beginning of the dormant period (December 2016) (I component of winter hardiness); return spring frosts $\left(-5.0-6.0^{\circ} \mathrm{C}\right)$ at the beginning of the growing season (March 2020) and during the flowering period $\left(-4.0-5.0^{\circ} \mathrm{C}\right)$ (April 2020) (IV component of winter hardiness).

According to the data obtained, the main stress for cherries, leading to significant damage and death of the generative organs, was sharp temperature drops in spring and almost annual frosts during the flowering period, and the later they appeared, the higher was the degree of their impact on the productive organs of sweet cherries.

According to the data obtained, the main stress for cherries, leading to significant damage and death of the generative organs, was sharp temperature drops in spring and almost annual frosts during the flowering period, and the later they appeared, the higher was the degree of their impact on the productive organs of the sweet cherry.

The year 2020 was abnormal for sweet cherry varieties, when in the spring there were two waves of frosts, similar in temperature, but having a different effect on the fruit organs. The first impact of stress - frost $\left(-5.0 \ldots-6.0^{\circ} \mathrm{C}\right)$ was noted on March 16, which led to the death of $50-60 \%$ of fruit buds. The rest of the undamaged fruit buds would allow a good harvest, however, recorded later, on April 13 , frosts $\left(-4.0 \ldots-5.0^{\circ} \mathrm{C}\right)$ led to severe freezing of almost all generative organs and the death of the crop. Since frosts coincided with flowering in most varieties of sweet cherry, the death of the generative organs of the flower was massive and irreversible, not only the pistil and stamens were affected, but the petals and even sepals were damaged. The death of generative organs in some varieties reached $95 \%$, and the remaining $5 \%$ of the ovaries provided the formation of an insignificant part of the yield $-2.3 \mathrm{~kg} /$ tree $(1.5 \mathrm{t} / \mathrm{ha})$ and the realization of the productive potential of varieties by $3.3 \%$. After this stress, a comparatively high yield $-4.0-4.5 \mathrm{~kg} /$ tree formed in the local varieties of cherries Sashenka, Volshebnitsa and Mak, which indicates their higher resistance to recurrent frost or IV component of winter hardiness. (Table 1). 
In 2016-2017 atypical for the beginning of the southern winter was the critical drop in air temperature to $-23.0^{\circ} \mathrm{C}$, which was recorded on December 17 , after a long warm period. Against the background of this stress - early winter frosts, when the resting phase had not yet begun in plants, the death of fruit buds was $90 \%$. But with such freezing, some varieties of sweet cherries also retained their harvest. It was low at $3.9 \mathrm{~kg} /$ tree $(2.6 \mathrm{t} / \mathrm{ha})$, and the realization of the productive potential was $5.6 \%$. (tab. 1).

Table 1. The yield of sweet cherry varieties, depending on the conditions of the year and varietal specifics in the Prikubanskaya zone of gardening of the Krasnodar region, planting scheme $5 \times 3 \mathrm{~m}$, rootstock - cherry seedlings (OPH "Tsentralnoe", 2017-2020)

\begin{tabular}{|c|c|c|c|c|c|c|}
\hline \multirow{2}{*}{ Сорт } & \multicolumn{6}{|c|}{ Yield, kg/tree } \\
\hline & $2016 / 2017$ & 2018 & 2019 & 2020 & $\mathrm{X}_{\mathrm{mn}}$ * & $\mathrm{t} / \mathrm{ha}$ \\
\hline $\begin{array}{l}\text { Extremal } \\
\text { temperatures } \\
\text { (stress) }\end{array}$ & $\begin{array}{c}\left(-23^{\circ} \mathrm{C}\right. \\
17.12)\end{array}$ & - & $\begin{array}{c}\left(-3,0 \ldots-3,5^{\circ} \mathrm{C}\right. \\
13.03)\end{array}$ & $\begin{array}{c}\left(-5,0 \ldots-6,0^{\circ} \mathrm{C}\right. \\
16.03) \\
\left(-4,0 \ldots-5,0^{\circ} \mathrm{C}\right. \\
13.04)\end{array}$ & & \\
\hline \multicolumn{7}{|c|}{ Early cultivars } \\
\hline $\begin{array}{l}\text { Krasnodarskaya } \\
\text { ranjaya }(\mathrm{k})\end{array}$ & 1.5 & 55.0 & 40.0 & 0.0 & 24.1 & 16.1 \\
\hline Madonna & 2.5 & 40.0 & 27.0 & 0.5 & 17.5 & 11.7 \\
\hline $\begin{array}{l}\text { Melitopolskaya } \\
\text { ranjaya }\end{array}$ & 4.0 & 30.0 & 14.0 & 0.0 & 12.0 & 8.0 \\
\hline $\begin{array}{l}\text { Kavkazskaya } \\
\text { uluchshenaya }\end{array}$ & 2.0 & 42.0 & 45.0 & 2.5 & 22.8 & 15.2 \\
\hline Mean in group: & 2.5 & 42.0 & 31.5 & 0.8 & 19.1 & 12.7 \\
\hline \multicolumn{7}{|c|}{ Mid-early cultivars } \\
\hline Valery Chkalov & 2.0 & 35.0 & 25.0 & 0.5 & 15.6 & 10.4 \\
\hline Kavkazskaya(k) & 3.5 & 30.0 & 18.0 & 3.0 & 13.6 & 9.1 \\
\hline Sashenka & 3.0 & 50.0 & 40.0 & 4.0 & 24.3 & 16.2 \\
\hline Mean in group: & 2.8 & 38.3 & 27.7 & 2.5 & 17.8 & 11.9 \\
\hline \multicolumn{7}{|c|}{ Middle cultivars } \\
\hline Volshebnitsa (k) & 6.0 & 50.0 & 45.0 & 4.5 & 26.4 & 17.6 \\
\hline $\begin{array}{l}\text { Rubinovaya } \\
\text { Kubani }\end{array}$ & 4.0 & 28.0 & 30.0 & 3.5 & 16.4 & 10.9 \\
\hline Tsentralnaya & 3.5 & 55.0 & 40.0 & 2.5 & 25.3 & 16.8 \\
\hline Talisman & 2.5 & 30.0 & 33.0 & 1.0 & 16.6 & 11.1 \\
\hline Mean in group: & 4.0 & 40.8 & 37.0 & 2.8 & 21.2 & 14.1 \\
\hline \multicolumn{7}{|c|}{ Late cultivars } \\
\hline Alaya (к) & 6.5 & 52.0 & 40.0 & 2.0 & 25.1 & 16.7 \\
\hline Dar isobiliya & 5.5 & 35.0 & 42.0 & 3.0 & 21.4 & 14.3 \\
\hline Mak & 6.5 & 27.0 & 35.0 & 4.5 & 18.3 & 12.2 \\
\hline Krupnoplodnaya & 6.0 & 50.0 & 35.0 & 2.0 & 23.3 & 15.5 \\
\hline Mean in group: & 6.1 & 41.0 & 38.0 & 2.9 & 22.0 & 14.6 \\
\hline $\mathrm{LSD}_{0,5}$ & 0.5 & 1.9 & 0.8 & 0.5 & 1.1 & 0.7 \\
\hline $\begin{array}{l}\text { Mean yield by } \\
\text { cultivars: }\end{array}$ & 3.9 & 40.5 & 33.5 & 2.3 & 20.2 & 13.3 \\
\hline $\begin{array}{l}\text { Realization } \\
\text { b.p.*, \% }\end{array}$ & 5.6 & 57.8 & 47.8 & 3.3 & - & - \\
\hline
\end{tabular}


Analysis of the data obtained showed that after exposure to temperature stresses, middle and late varieties of sweet cherries were less damaged. So the middle variety Volshebnitsa and the later ones - Alaya, Krupnoplodnaya and Mak showed great plasticity, which is confirmed by a yield of 6.0-6.5 kg/tree (Table 1 ).

A comparative assessment of the yield of varieties by years, made it possible to determine that in a favorable 2018, when there was no stress, the average yield of sweet cherry varieties was high and averaged $40.5 \mathrm{~kg} /$ tree $(27 \mathrm{t} / \mathrm{ha})$. The potential of sweet cherry varieties in 2018 was realized by a maximum of $57.8 \%$. The yield varied from $27.0 \mathrm{~kg} /$ tree in the Mak variety, up to $55.0 \mathrm{~kg} /$ tree in the Krasnodarskaya ranjaya variety, which confirms the influence of the genotype, which determines the degree of setting of fruit buds, along with weather conditions. Thus, a high yield of 50.0-55.0 kg/ tree the varieties Sashenka, Volshebnitsa, Centralnaya, Krupnoplodnaya were distinguished. The yield of sweet cherry varieties Mak and Rubinovaya Kuban was lower and amounted to 27.0-28.0 $\mathrm{kg} /$ tree (Table 1).

2019 was also characterized by frosts at the level of $-3.0-3.5^{\circ} \mathrm{C}$, noted on March 13 , i.e. a month earlier than in 2020. However, they were not detrimental to the future sweet cherry harvest, thus, freezing of fruit buds amounted to $30 \%$, which made it possible to form a yield of $34.0 \mathrm{~kg} /$ tree $(22.6 \mathrm{t} / \mathrm{ha})$ and realize the production potential of varieties at the level of $47.8 \%$. In 2019, varieties Krasnodarskaya ranjaya, Kavkazskaya uluchshenaya, Dar Izobiliya, Sashenka, Volshebnitsa, Tsentralnaya and Alaya showed a higher adaptability to frost, the yield of which was $40.0-45.0 \mathrm{~kg} / \mathrm{tree}$. (Table 1).

Statistical processing of the data showed a high correlation dependence $\left(R^{2}=0.97\right)$ of the yield of sweet cherry varieties with average monthly temperatures in March, which is associated with the fact that frosts occurred twice in the second decade of March. Also, regression analysis showed a direct dependence of the death of generative organs, and therefore, a decrease in the yield of sweet cherry varieties under the influence of any type of stress $\left(\mathrm{R}^{2}=0.9\right)$.

\section{Conclusion}

Under the conditions of the southern region, the main stress factors for cherries were: recurrent late frosts and early exposure to frosts after a warm autumn, when the plants had not yet had time to pass to dormancy. Against the background of late return frosts, the death of the generative organs of sweet cherry was $95 \%$, the realization of the productive potential $-3.3 \%$; after early spring frosts, freezing of cherry fruit buds was $30 \%$, the realization of productive potential $-47.8 \%$. After exposure to early winter frosts, the death of cherry fruit buds was $90 \%$, the realization of the productive potential $-5.6 \%$. Mathematical analysis showed a high correlation $\left(\mathrm{R}^{2}=0.97\right)$ of the productivity of varieties from abnormal temperatures in March and from the degree of exposure to stress, i.e. damage to generative organs $\left(\mathrm{R}^{2}=0.9\right)$.

Under stressful weather conditions in the south of Russia, the domestic varieties Alaya, Sashenka and Volshebnitsa, which are recommended for creating sustainable plantings of cherries, showed a high degree of realization of the productive potential of sweet cherries.

\section{References}

1. R. Zaremuk, Y. Dolya, BIO Web Conf., 25, 02004 (2020) http://doi.org/10.1051/bioconf/20202502004

2. T.N. Doroshenko, L.G. Ryazanova, S.S. Chumakov, Z.Z. Zainutdinov, Scientific Journal of KubSAU, 159, 294-302 (2020) http://doi.org/10.21515/1990-4665-159-020 
3. Q.J. Zhang, D.J. Gu, K.H. Yu, Z.H. Zhou, Acta Hortic., 1208, 221-225 (2018) https://doi.org/10.17660/ActaHortic.2018.1208.29

4. F.M. Chmielewski, K.P. Götz, K.C. Weber, S. Moryson, Int. J. Biometeorol., 62, 217-228 (2018) http://doi.org/10.1007/s00484-017-1443-9

5. J.O. Alhamid, C. Mo, X. Zhang, P. Wang, M.D. Whiting, Q. Zhang, Biosyst. Eng., 172, 124-133 (2018) https://doi.org/10.1016/j.biosystemseng.2018.06.006

6. E.V. Tarasova, Acta Hortic., 1242, 931-935 http://doi.org/10.17660/ActaHortic.2019.1242.136

7. C. Zlati, M. Istrate, R. Pascu, R. Bernardis, Lucrari strintifice sepia horticultura, 62(2), 69-74 (2019) https://repository.uaiasi.ro/xmlui/handle/20.500.12811/238

8. A. Taranau, Z. Kazlouskaya, I. Palubiatka, Fruit Growing Research, 34, 63-66 (2018) http://doi.org/10.33045/fgr.v34.2018.12

9. L. Hillmann, T. Einhorn, M. Blanke, Erwerbs-Obstbau, 62, 163-174 (2020) https://doi.org/10.1007/s10341-020-00485-y

10. L. Szalay, A. Molnár, S. Kovács, Sci. Hortic., 214, 228-232 (2017) https://doi.org/10.1016/j.scienta.2016.11.039

11. R. Salazar-Gutiérrez, B. Chaves, G. Hoogenboom, Sci. Hortic., 198, 344-351 (2016) https://doi.org/10.1016/j.scienta.2015.12.003

12. M. Szymajda, K. Pruski, E. Zurawicz, M. Sitarek, Can. J. Plant Sci., 93(2), 191-198 (2013) http://doi.org/10.4141/cjps2012-238

13. O. Kaya, C. Kose, V. Donderalp, T. Gecim, S. Taskın, Sci. Hortic., 270, 109403 (2020) https://doi.org/10.1016/j.scienta.2020.109403

14. O. Kaya, C. Kose, M. Sahin, Int. J. Biometeorol., 65, (2021) https://doi.org/10.1007/s00484-021-02093-1

15. E. Dziedzic, M. Bieniasz, B.Kowalczyk, Sci. Hortic., 251, 127-135 (2019) https://doi.org/10.1016/j.scienta.2019.03.013 